them surpasses all the others, and has an intensity which we may call I. It is situated in the direction A. The next maxima, one on either side of the principal one, have intensity $I^{\prime} / 9$, where $I^{\prime} / I=4 / \pi^{2}$; the next pair beyond these have intensity $I^{\prime} / 25$; and so on-the intensities of the lateral maxima decreasing inversely as the squares of the odd numbers. These are consequences of the theory of diffraction gratings. From the above law it follows that the maxima soon become much too faint to be seen by the eye, or to affect a photographic plate, so that what alone can be made visible is the group in the immediate neighbourhood of the position $A$. This group is what seems to be represented on a very large scale in some of Prof. Michelson's figures, but which in our spectroscopes is so compressed laterally that the whole group appears like one line.

A similar group is necessarily substituted for each physically single line wherever there is one of those limitations of aperture which must occur within the interferometer itself, and, in fact, in every optical instrument. In the astronomical telescope it occasions the spurious disc of a star with its attendant rings. The only question is whether the intervals between the maxima of the group are sufficiently wide to be detected by the interferometer; and as this is simply a question of aperture, or, in the case of a grating, of the number of rulings, it follows that these instrumental groups may be distinguished from physically real groups by the circumstance that the maxima present in them will become more widely spaced if the aperture (or number of rulings) is reduced.

II. An apparently double line.-Where the apparatus employed limits the aperture at only one place, the group, which will be substituted for a physically single line, is that described above ; at least, if the instrument is in adjustment. But if the arrangements are such as to introduce an actual or virtual limitation of apertures at two places, a double line may result, accompanied by faint appendage lines. What then occurs was discussed in a communication made by the writer to the British Association in 1894 (see Report of the Oxford meeting, p. 583 ; when also were exhibited examples of such spurious double lines coarse enough to be seen without an interferometer, and where the appendage lines predicted by theory were also seen when the light was intense.

The foregoing instrumental effects arise when the apparatus is accurately collimated. If it be much out of adjustment the groups, substituted for a really single line, are more complicated. But whatever they may be, it is certain that if the resolving power of the interferometer can go sufficiently far, it will bring them into view if they are sufficiently bright to be seen, and that we must then be on our guard against mistaking a resolution of this kind for evidence that the line under examination is physically multiple.

8 Upper Hornsey Rise, N, January 13.

THE remarks put forward by Dr. Stoney are the well-known results of the wave theory, and Prof. Michelson, no doubt, is quite familiar with all that has been said in this department. In addition, he alone is quite familiar with what it is that is actually observed in his interferometer, and therefore must be in a position to give a strong opinion as to whether the observed effects are spurious and due to diffraction or not.

It was with this feeling that I wrote my remarks (p. 228), and I wished to draw some further information from Prof. Michelson on this important subject, rather than in any way to cast doubt on the correctness of his conclusions. I have never worked with the interferometer, and therefore cannot pronounce upon its performance as an optical instrument, but I trust Dr. Stoney's interesting and important observations may have the effect of drawing a full explanation of all the outstanding difficulties.

Bardowie, Orwell Park, Dublin. ThOMAS PRESTON.

\section{A Note on Catching Insects, and the Behaviour of the Bulldog-Ant of South Australia.}

DURING my visit to South Australia, I wished to obtain some specimens of the insects of the country, for my naturalist friends at home. At first I experienced considerable difficulty in catching those whose movements were rapid, without injuring their bodies. Recently I have been able to secure nearly every specimen seen, by the following method.

A small antitoxin syringe was charged with benzol, and a small jet of the liquid was directed towards the beast sought for (a large tarantula, for example); the result of this form of attack was to render the beast almost instantly inert, so that it was easily secured. I am not at all sure that benzol is the best liquid for the purpose ; but I used it, as it happened to be the only substance I could obtain, at a distance from a township, which appeared likely to produce the desired effect. I find that insects which could be easily captured a month ago when it was fairly cool, have become wonderfully active now that the sunshine temperature is about $150^{\circ}$ to $155^{\circ} \mathrm{F}$.

I placed a large bulldog-ant, about one inch in length, in a glass bottle three and a half inches in diameter; I noticed that when the bottle was on its side, and the ant was clinging to the upper surface of the bottle, with its back pointing downwards, that if the ant was detached by a slight jerk, it fell on its feet. I repeated this experiment many times, with seven different bulldog-ants ; in every case the ant fell feet downwards, after the well-known manner of a cat.

As I am no naturalist, I may be describing an acrobatic movement of the bulldog-ant already well known to students of natural history. But even should this be so, probably the fact I have mentioned may be of interest to others.

FREDK. J. JeRVIS-SMith.

Quanbi, Mt. Barker, South Australia, December I6, I898.

\section{A New Dome for Equatorials.}

WITH reference to the note in NATURE of January I2 (p. 257), on "A New Dome for Equatorials," allow me to point out that a rotary dome without a shutter was, as far as I know, first constructed for the observatory in Strassburg. The late Prof. Winnecke, at the meeting of astronomers in Berlin on September 5, 1879, referred to it as follows (Vierteljahrsschrift der Astronomischen Geselischaft, I4 Jahrgang, p. 334): "In consequence of the construction of the altazimuth, in which the telescope was placed at the end of the axis, the dome of the north tower had to have an unusually large aperture. This was easily accomplished by employing two separate halves of a hemisphere, which could be rolled back on wheels situated above the circular rail, by which means a complete aperture of $2 \frac{1}{2}$ metres could be obtained. The mechanism for the movable parts works easily and surely."

The same construction is described in the Annalen der Kais. Univ. Sternwarte in Strassburg, vol. i. p. 7; an illustration of this will be found on Plate vii. (the dome to the left): although both domes - that to the right holding a small refractor, viz. a comet-secker-are represented as closed, the difference can be seen at once.

I trust that this short historical remark may be mentioned in the next number of NaTuBF.

E. BECKER.

Kais. Univ. Sternwarte, Strassburg, i. E., January in.

\section{Luminosity of Sugar.}

THE communication of Mr. J. Burke to the British Association, on the luminosity of sugar (NATURE, vol. Iviii. p. 533) recalls to my mind an illustration on the large scale of the same interesting phenomenon.

In the process of making what is known as granulated sugar, ordinary refined sugar is passed through a revolving sheet-iron cylinder, where it meets with a current of hot air, and is warmed and dried at the same time. On leaving the drying cylinder the sugar is taken by a travelling band, or other carrier, and dropped into a hopper, from whence it is drawn for packing. The sugar falling into the hopper soon forms a pyramidal heap, and when this is examined in darkness, the top of the heap, where the stream of sugar lands, is seen to glow with a steady light blue luminosity.

On rubbing two pieces of ordinary lump or tablet sugar together, in darkness, the glow is readily produced, and when a piece is broken in two there is a bright flash at the moment of fracture. The light produced in this manner is not affected by moistening the lumps with alcohol, but is intensified when water is used.

When hard lumps of sugar are crushed by striking with any solid body, such as a shovel, the glow appears as a flash, and is easily seen even in the presence of dull light, but is, of course, best viewed in complete darkness. Even a heap of loose sugar responds to a blow from a shovel.

Sometimes sugar, as purchased retail, when left in the bag during dry weather, sets to a hard mass. On scraping such with

NO. I 526, vOL. 59] 